\title{
A QUESTÃO DA DIFERENÇA E DAS RELAÇÕES EM RICHARD HARTSHORNE
}

\author{
THE QUESTION OF DIFFERENCE AND RELATIONS \\ IN RICHARD HARTSHORNE
}

\author{
LA CUESTIÓN DE LA DIFERENCIA Y DE LAS \\ RELACIONES EN RICHARD HARTSHORNE
}
Denis Castilho - Universidade Federal de Goiás - Goiânia - Goiás - Brasil
deniscastilho@hotmail.com

\section{Resumo}

As proposições teóricas do geógrafo estadunidense Richard Hartshorne são um convite à reflexão. Baseadas principalmente nas concepções de Alfred Hettner, constituem-se como importante contribuiçãa ao estudo da natureza da Geografia, tal como indica o próprio título de seu trabalho publicado em 1939, The Nature of Geography: A Critical Survey of Current Thought in the Light of the Past. A preocupação com a essência dessa disciplina levou 0 autor a apresentar, neste e em um texto de 1959 (Perspective on the Nature of Geography), uma sistematização de ideias e proposições de importantes clássicos do pensamento geográfico que 0 antecederam, especialmente do século XIX. Dentre os principais conceitos apresentados nessas publicações, destacam-se o de diferenciação de área, bastante difundido (e confundido) entre os geógrafos, e os de relação e conexão, muito vinculados pelo autor à questão sempre reiterada em seus trabalhos: aquela referente ao caráter variável da superfície terrestre. Com base nessas premissas, este trabalho apresenta uma análise desses conceitos, discute seus limites teóricos e evidencia questões relacionadas às suas possibilidades analíticas.

Palavras-chave: Richard Hartshorne, diferenciação, relação, conexão.

\section{Abstract}

The American geographer Richard Hartshorne's theoretical propositions are an invitation to reflection. Based primarily on Alfred Hettner's conceptions, they constitute a significant contribution to the study of the nature of geography, as indicated by the very title of his work published in 1939, The Nature of Geography: A Critical Survey of Current Thought in the Light of the Past. The concern with the essence of this discipline has led the author to present in this book and in a text from 1959 (Perspective on the Nature of Geography), a systematization of ideas and propositions from important classics of the geographical thought that preceded him, particularly from the nineteenth century. Amongst the main concepts presented in these publications, the highlight are areal differentiation - widely disseminated (and misunderstood) among geographers - and the notions of relation and connection, largely related to the question constantly reiterated in his works - i.e., the variable character of the earth surface. Based on these premises, this paper lays out an analysis of these concepts, discusses their theoretical limits, and underlines the issues related to their analytical possibilities. Keywords: Richard Hartshorne, differentiation, relation, connection.

\section{Resumen}

Las proposiciones teóricas del geógrafo estadounidense Richard Hartshorne son una invitación a la reflexión. Basadas principalmente en las ideas de Alfred Hettner, constituyen una importante contribución al estudio de la naturaleza de la geografía, como lo indica el título de su obra publicada en 1939, The Nature of Geography: A Critical Survey of Current Thought in the Light of the Past. La preocupación con la esencia de esta disciplina 
llevó al autor a presentar en este y em otro texto de 1959 (Perspective on the Nature of Geography), una sistematización de ideas y propuestas de importantes clásicos del pensamiento geográfico, sobre todo del siglo XIX. Entre los principales conceptos presentados en estas publicaciones, destacamos el de la diferenciación espacial, generalizado (y confundido) entre los geógrafos, y los de relación y conexión, muy vinculados por el autor a la cuestión de estúdio siempre reiterado en sus obras: la referencia al caráter variable de la superficie terrestre. Con base en estas premisas, el artículo presenta un análisis de estos conceptos, discute sus límites teóricos y destaca sus posibles aplicaciones analíticas.

Palabras clave: Richard Hartshorne, la diferenciación, la relación, la conexión.

Introdução

Após o lançamento de sua clássica obra The Nature of Geography, em 1939, Richard Hartshorne costumava dizer que seu trabalho fora desenvolvido no sentido de evidenciar o caminho que muitos pensadores haviam trilhado e as impressões que eles deixaram acerca da Geografia. Para Hartshorne, seu estudo, portanto, não tinha a pretensão de expor uma tese pessoal sobre o que deveria ser a Geografia, mas demonstrar o que outros autores, especialmente do século XIX, defendiam ser a tarefa dessa disciplina. Observações como essa constam no memorial sobre sua vida, escrito por Geoffrey Martin e publicado em 1994 nos anais da Association of American Geographers.

De fato, a preocupação com a natureza da Geografia e o desafio de aclarar o seu papel e lugar entre as diferentes áreas do conhecimento realmente levaram o geógrafo estadunidense a apresentar um cenário geral da disciplina, considerando o que havia sido produzido até então por importante parcela de pensadores ligados à Geografia, e o que eles acreditavam ser a tarefa dessa disciplina. Entretanto, por mais que o exercício de síntese metodológica tenha sido verdadeiro (e necessário), as conclusões de Hartshorne e suas proposições para a Geografia não se mostraram imparciais nem significaram, necessariamente, um direcionamento aberto às diferentes concepções de seus predecessores - até porque é evidente o seu posicionamento e a opção por difundir (aprofundar e rever, em alguns casos) a mensagem teórica de um autor em especial, Alfred Hettner. Os principais conceitos de Hartshorne, por exemplo, demonstram uma clara filiação às concepções do geógrafo alemão e, por conseguinte, ao neokantismo. Isso justifica o seu conceito de região e, na mesma direção, os contrapontos com alguns geógrafos franceses.

Os fundamentos metodológicos de Hartshorne, nesse sentido, guardam o peso de seus méritos e, evidentemente, ajudam-nos a compreender 
as suas opções teóricas e o modo como essas opções permitiram-lhe desenvolver alguns importantes conceitos presentes em sua obra, tais como diferenciação de áreas, bastante difundido (e confundido) entre os geógrafos, e relação e conexão, os quais se apresentam como essenciais à questão hettneriana reiterada e fundamentada por Hartshorne: aquela que diz respeito ao caráter variável da superfície terrestre. Esses conceitos estão alicerçados em um sistema de pensamento muito bem estruturado e relevante para o arcabouço teórico da Geografia, mas que merece algumas observações no sentido de evidenciar a sua possibilidade analítica como também seus limites teóricos. Apresentar tais conceitos e delinear essas observações é o que propomos neste trabalho.

\section{0 percurso do autor e seu interesse pela natureza da Geografia}

Richard Hartshorne é daqueles nomes que marcaram os estudos sobre a história e natureza da Geografia. Nascido em Kittanning, Pensilvânia, em 12 de dezembro de 1899, foi criado em um ambiente familiar que muito cultivava o conhecimento bíblico. Um de seus cinco irmãos, Charles, viria a ser um importante filósofo. Geoffrey Martin (1994) relata que Richard teve brilhante desempenho no período escolar, tendo ganhado concursos de oratória (inclusive em alemão) e um prêmio na área de matemática, o que provavelmente o levou a cursar essa disciplina na Universidade de Princeton. Apesar do prêmio e da graduação, Hartshorne dizia que seu interesse era mais voltado para assuntos humanos, especialmente quando conheceu a obra do professor de Geografia da Universidade de Yale, Ellsworth Huntington, pesquisador de temas relacionados ao crescimento econômico, ao clima etc. e com quem manteve contato por cartas.

Seguindo sugestões desse professor, Hartshorne foi estudar Geografia em Chicago, onde teve aulas com Harlan Barrows, então chefe do departamento, defensor da Geografia como "ecologia humana" e pesquisador de temas como história da Geografia e conservação de recursos naturais. Hartshorne frequentou cursos com Ellen Semple, Derwent Whittlesey e o inglês James Fairgrieve, os quais despertaram nele o interesse pela Geografia política ${ }^{1}$ (Martin, 1994). Mas foi com Charles Colby e Wellington Jones, seu orientador, que Hartshorne manteve maior proximidade. Segundo Martin (1994, p. 481, tradução nossa), “os cursos de Charles Colby sobre a América do Norte se constituíram na apresentação 
da Geografia regional a Hartshorne”. Nesse momento ele já demonstrava interesse pela natureza da Geografia, mas seus estudos estavam voltados à pesquisa de doutorado dedicada ao porto de Chicago, com a qual recebeu o título de doutor com grande louvor em agosto de 1924 .

Após a conclusão do doutorado, Hartshorne trabalhou durante dezesseis anos em Minnesota, onde ensinou Geografia econômica e desenvolveu estudos sobre localizações e temas relacionados aos transportes. Hartshorne manteve seu interesse pela Geografia política mesmo em um país com reduzido número de geógrafos efetivamente engajados nessa área. Carl Sauer, por exemplo, um dos grandes nomes da Geografia estadunidense da época, não dava margens para o desenvolvimento da Geografia política em seu meio (Martin, 1994). Além disso, Hartshorne (1939) argumenta que as discussões sobre a natureza da Geografia nos Estados Unidos até a década de 1930 geralmente não consideravam a herança teórica da disciplina, mesmo sendo um conhecimento antigo e imbuído de certa organização em sua estrutura. A negligência com o histórico dessa ciência e a ausência de autores pioneiros nos (poucos) estudos epistemológicos da Geografia estadunidense foram pontos bastante criticados por Hartshorne. Talvez por isso ele tenha voltado seus esforços para geógrafos, segundo ele, mais claros e coerentes com a ciência geográfica, a exemplo dos clássicos e pioneiros pensadores alemães. A investigação dos trabalhos desses autores permitiu-lhe conhecer, por exemplo, a obra de Hettner.

Na década de 1930, em função de seus estudos na área da Geografia política, recebeu bolsa para estudar fronteiras políticas na Europa. Hartshorne viajou até o Velho Continente, mas, em função das condições políticas instáveis daqueles tempos, não encontrou ambiente propício para examinar as fronteiras políticas in loco. Foi por isso que, como observa Arcassa (2013), Hartshorne aproveitou a viagem para desenvolver uma ampla pesquisa em diversas bibliotecas da Europa e manter contato com inúmeros estudiosos. Um pequeno ensaio que já havia sido produzido por ele ainda nos Estados Unidos foi ampliado durante sua permanência em solo europeu. Em seguida, retornou aos Estados Unidos com um manuscrito de centenas de páginas, contendo uma profunda e detalhada análise sobre a evolução do pensamento geográfico. Tratava-se da importante obra The Nature of Geography. Antes de passar o trabalho a Whittlesey, que havia prometido publicá-la nos Anais da Association of American 
Geographers, Hartshorne teria utilizado bibliotecas das universidades de Harvard e Clark para concluir seu trabalho (Martin, 1994).

Após a publicação de The Nature of Geography, o livro foi amplamente lido por professores e estudantes de Geografia de todo o país. Encontros e seminários foram organizados em torno de suas ideias e muitos estudiosos estrangeiros também manifestaram seus elogios à Hartshorne. Nas observações de Lima Neto (2012), o conceito de ciência e a relevância da região no interior do pensamento geográfico estadunidense devem-se, em particular, à obra clássica de Hartshorne, que foi traduzida para o alemão, japonês e espanhol.

Com o tempo, as observações, ponderações e discordâncias ao livro começaram a aparecer. Segundo o próprio Hartshorne, não seria um texto para iniciantes - ele mesmo pôde conferir, em conversas e reunióes, a dificuldade de seus alunos em compreender o conteúdo. Seu propósito, segundo Martin (1994), era fornecer uma abordagem metodológica para os problemas que confrontavam geógrafos, assim como contribuir com a compreensão do desenvolvimento da Geografia e oferecer um resumo sistemático do que esses pensadores acreditavam que a disciplina deveria ser.

Em 1940, Hartshorne aceitou um cargo de professor na Universidade de Wisconsin, onde trabalhou até sua aposentadoria em 1970. Nesse intervalo, foi presidente da Associação de Geógrafos Americanos em 1949, tendo recebido a máxima distinção da associação em 1960. Nas duas primeiras décadas em que Hartshorne trabalhou em Wisconsin, sua obra teve uma ampla recepção por parte da comunidade geográfica, mas também enfrentou críticas contundentes, das quais Coscioni (2015) destaca as de Sauer (1941) e Schaefer (1953). Em resposta às críticas e correspondências com diferentes autores, mas também em virtude da necessidade de elaborar um trabalho mais esclarecedor sobre os princípios da Geografia, Hartshorne publicou, em 1959, o livro Perspective on the Nature of Geography, em que reconsidera e aprofunda dez questões abordadas na publicação de 1939. Essa foi, segundo Moraes (2002, p. 87), “a última tentativa de agilizar a Geografia Tradicional, mantendo-lhe a essência de busca de um conhecimento unitário, e dando-lhe uma versão mais moderna”. Produto de muitos debates e correspondências, o próprio autor considerava-o uma espécie de continuidade e conclusão do trabalho publicado em 1939.

Diante das proposições teóricas das duas publicações, alguns autores, a exemplo de Moreira (2008) e Arcassa (2013, 2014), apontam 
como conceitos de referência em Hartshorne as noções de área e diferença. Capel (2012), por sua vez, assinala que, do mesmo modo que em The Nature of Geography, Hartshorne trouxe novamente sua polêmica com as correntes neopositivistas na publicação de 1959, em que concebe diferenciação de área e associação de fenômenos em um território concreto como a chave de sua concepção geográfica. Além disso, é necessário evidenciar a importância dada pelo próprio autor aos conceitos de relação e conexão, uma vez que a possibilidade de explicação do caráter variável da superfície terrestre passa por eles. O diálogo e a interpretação das concepções de Hartshorne sobre o pensamento geográfico, evidentemente, estão em aberto. É em virtude da riqueza de seus conceitos, mas também da necessidade de problematizá-los, que apresentamos, a seguir, algumas questões necessárias.

Relação e conexão: importantes elementos da questão

Se há o caráter variável da superfície terrestre, também há o “caráter único” dos lugares (Hartshorne, 1951, p. 264). Todavia, eles são únicos não porque independem uns dos outros, mas porque existem múltiplos fenômenos heterogêneos que variam na superfície terrestre, inter-relacionados num mesmo lugar e interconectados em lugares diferentes. ${ }^{2}$ Relações e conexões, portanto, convergem e dão sentido à integração, às trocas, às transformações e à funcionalidade dos lugares. O caráter variável da superfície terrestre resulta desse processo. Variável não apenas pela sua forma, mas essencialmente por seu aspecto humano, porque, afinal, relações e conexões emergem, sobretudo, da ação. É por isso que, para Hartshorne, o que está em questão na Geografia não é necessariamente um objeto ou categoria específica de fenômeno. Também podemos afirmar com segurança que não se trata exatamente de uma área específica, mas do perfil dinâmico que permite interpretar a variabilidade de integração entre fenômenos nessa área (ou noutras) ou, enfim, o caráter variável da superfície terrestre. Nas palavras de Hartshorne (1978, p. 79), “a Geografia se preocupa com os aspectos não em si mesmos, mas na sua qualidade de elementos de integração em áreas", ou que variam de lugar a lugar.

Hettner também havia dado especial atenção às relações, como nesta passagem: 
[...] se não existisse nenhuma relação causal entre diferentes lugares da Terra [Erdstellen], e se os diferentes fenômenos fossem independentes um do outro em um e mesmo lugar da Terra [Erdstelle], não seria necessária nenhuma concepção corológica particular. Já que, contudo, existem tais relações que não são concebidas de modo algum ou apenas acessoriamente pelas ciências sistemáticas e pelas históricas, é necessária uma específica ciência corológica da Terra ou da superfície terrestre. (Hettner, 2011b, p. 144).

Essa ciência é a Geografia, conclui o estudioso alemão. Mas, a respeito dessas considerações, Hettner (2011a, p. 139) declara: "se o caráter essencial da investigação geográfica consiste no fato de que ela é corológica, não se pode falar ainda assim de um método corológico”. Segundo ele, método pressupõe o caminho em direção a um objetivo. Não é o caminho que é corológico, adverte Hettner, mas sim o objetivo, o próprio objeto da Geografia. ${ }^{3}$ É por isso que sua preocupação "consiste em conhecer o caráter das regiões e lugares, o que pressupõe compreender a existência das inter-relações dos diferentes domínios da realidade e suas variadas manifestações” (Hettner, 1927 apud Hartshorne, 1978, p. 14).

Também interessado pelas relações causais e pelas variações, mas com uma discussão mais voltada ao plano metodológico, Hartshorne defende que o foco da Geografia não diz respeito a qualquer espécie de variação ou simplesmente à área ou superfície terrestre como realidade física. A Geografia, na concepção do autor, "é a disciplina que procura interpretar o caráter variável da terra, de lugar a lugar, como o mundo do homem” (Hartshorne, 1978, p. 51). Além disso, a diferenciação de áreas, ao contrário do que se costuma dizer, não é uma simples descrição das "diferenças" ou das formas e fenômenos de um dado lugar. Significa entender fundamentalmente relações de fenômenos em determinada área e conexões (ou inter-relações) entre fenômenos em áreas diferentes.

A discussão sobre o conceito de diferenciação de áreas é apresentada por Hartshorne em The Nature of Geography, em um artigo de 1958, “The Concept of Geography as a Science of Space, from Kant and Humboldt to Hettner", e em Perspective on the Nature of Geography, onde rebate algumas críticas que, segundo ele, estiveram direcionadas muito mais ao termo do que ao conceito. A ideia de diferenciação de áreas, muito discutida pelo autor, guarda vínculos com as concepções de Hettner, sobretudo no que diz respeito ao papel das relações: "As conexões ou relações causais entre fenômenos da Geografia, conforme observou Hettner em 1905, são de 
duas espécies: as relações mútuas que existem entre diferentes fenômenos, num mesmo lugar, e as relações ou conexões entre fenômenos em lugares diferentes" (Hartshorne, 1978, p. 20, grifo nosso).

É interessante observar que o conceito, analisado em diferentes obras e discussões de Hartshorne, mantém a importância atribuída às relações, como nesta passagem: "o nosso propósito, em Geografia, não é o estudo dos fenômenos em si mesmos, mas dos fenômenos em suas relações" (Hartshorne, 1978, p. 85). Em 1949, tendo sido convidado para apresentar seus argumentos na oitava reunião ordinária do Comitê de Geografia, o qual havia sido montado para discutir os rumos da disciplina em Harvard, Hartshorne também chamou atenção para a importância das relações. Disse que, "ao considerar o problema de qualquer lugar, o geógrafo sempre tem em mente sua relação com outras áreas circundantes e com outras áreas do mundo" (Glick, 1985, p. 36, tradução nossa). ${ }^{4}$

Essa preocupação com as relações, ou com o que podemos chamar de escalas de relações, permite falar de uma Geografia que não negligencia os processos nem, portanto, o movimento. Elementos como a água, o ar e até mesmo os animais movem-se e produzem conexões. Com a introdução do homem na cena, escreve Hartshorne (1978, p. 20), “esse aspecto dinâmico do caráter das áreas se torna muito mais importante, porque constitui um dos atributos particulares do homem o fato de que ele não apenas se desloca de um lugar para outro, mas também põe as coisas em movimento”. Essa observação é emblemática porque as áreas diferem não apenas em sua morfologia, mas em seus aspectos humanos, conclui Hartshorne. É desse arranjo envolvendo ação, relação e conexão, portanto, que surge o sentido funcional das áreas. Não por acaso, Hartshorne desenvolveu pesquisas sobre temas relacionados a transportes e logística, como atestam sua tese sobre o porto de Chicago (The Port of Chicago: Its Commerce, Facilities, and Requirements) e sua investigação sobre localização (Hartshorne, 1927).

A ideia de inter-relação está presente até mesmo na obra de Ritter, como observa Hartshorne (1978, p. 30):

Nas análises de Ritter, a heterogeneidade dos fenômenos foi não só aceita, mas acentuada como característica essencial da Geografia. A matéria encontra sua unidade e especificidade, como campo de conhecimento, através do estudo do caráter das áreas, determinado pela multiplicidade de aspectos que, em suas inter-relações, recobrem as áreas da superfície terrestre. 
A importância dada às relações por Hartshorne suscitou algumas críticas. Alguns leitores entendiam (erroneamente) a ideia de relação como uma reincidência do princípio da "relação entre natureza e homem" vinculada à polêmica determinista. $\mathrm{O}$ "trauma" determinista possivelmente influenciou essas críticas, mas especialmente a incompreensão acerca do sentido e papel das relações no campo da Geografia, assegura Hartshorne (1978). Atribuir à Geografia o estudo dos aspectos complexos formados pelos fenômenos inter-relacionados não significa dizer que a relação é o objeto de seu estudo ou o fim da investigação. Todavia, negligenciar as inter-relações ou conexões implica decretar à Geografia o simples papel de compêndio enciclopédico de reduzido valor intelectual, adverte o autor. Por isso, relações e conexões devem ser pensadas como elementos essenciais que permitem interpretar o caráter variável dos lugares. O conceito de variação espacial ou diferenças entre áreas, assim, depende diretamente da ideia de relação e conexão. A variação das formas e de características de movimentos, no entanto, deve ser considerada não apenas no contexto das interações entre diferentes espaços - aqui nos remetendo às conexões -, mas também ao que Hettner chama de relações mútuas, estabelecidas entre diferentes fenômenos em um mesmo lugar.

Disso surge uma questão: que relações devem ser consideradas? Se a preocupação da Geografia é voltada ao caráter variável das áreas e não a um objeto específico, o que deve ser interpretado? Primeiramente é importante lembrar que, na concepção de Hartshorne, área (ou região) é fruto de um recorte realizado pelo pesquisador. Assim como espaço, para Kant, constitui uma representação a priori que fundamenta os fenômenos externos (Santos, 2002), região é, para Hartshorne, um pressuposto das intuições externas. A natureza da distinção, nesse sentido, é determinada no processo de investigação. A multiplicidade de processos e relações mútuas entre fenômenos nessa área, assim como a conexão entre fenômenos desta com fenômenos de outras áreas, são amplas demais para serem apreendidas. É impossível apanhar o complexo total de integrações que se estabelecem em uma mesma área. O caminho da escolha, obviamente, passa pela observação, mas demanda métodos sistemáticos e objetivos de seleção. $\mathrm{O}$ fato é que uma gama extensa de fenômenos inter-relacionados pode chamar a atenção do geógrafo, uma vez que a seleção e análise dependem do pesquisador e das características específicas das variações. A escolha do que analisar, por esse motivo, é relativa. Já a preocupação 
central é mantida: interpretar as integrações entre fenômenos que variam de lugar a lugar, mas ciente de que o interesse por essa variação advém de sua significância para o homem. Como bem observa Hartshorne (1978, p. 50):

Qualquer fenômeno é significante em Geografia na extensão e no grau em que suas inter-relações com outros fenômenos do mesmo lugar, ou suas interconexões com fenômenos de outros lugares, determine as variações espaciais daqueles fenômenos e, portanto, a totalidade de variação da área, medida em referência à sua significância para o homem.

Além disso, Hartshorne ainda defende que todas as ciências são meras parcelas de um corpo de conhecimento. Cada uma representa um ponto de vista. A questão que se coloca à Geografia, nesses termos, além do tipo de variação que lhe interessa ser medida pela sua significância para o homem, não diz respeito se ela deve voltar-se às relações mais simples ou complexas ou se ela é sistemática (geral) ou específica (regional). O dualismo deve ser evitado porque, segundo o autor, "verifica-se uma gradação ao longo de um continuum, desde os estudos que analisam os complexos mais elementares em variação espacial através do mundo, até os que analisam as mais complexas integrações em variação espacial dentro dos limites de áreas reduzidas” (Hartshorne, 1978, p. 129). O estudioso "poderá estar interessado, em maior ou menor grau, tanto em resultados genéricos, quanto em individuais" (p. 173). É preciso ter em mente se o propósito consiste em obter conclusões genéricas ou examinar um caso individual. No primeiro, destacam-se os estudos tópicos, e, no segundo, os estudos regionais, com maior possibilidade de conhecimento detalhado do local. Tendo isso em vista, se a Geografia precisa de ambos os tipos de estudos, sendo em parte nomotética e em parte idiográfica, Hartshorne tem razão ao dizer que há pouca significação em procurar avaliar a importância relativa desses dois tipos. Com isso, ele também procura superar o dualismo em Geografia - uma divisão prejudicial ao desenvolvimento da disciplina - articulando as escalas de interpretação de acordo com a natureza das integrações entre fenômenos escolhidos para alcançar a compreensão das variações.

É comum a preocupação, por parte da comunidade acadêmica, com a formulação de conceitos generalizantes e de leis científicas ou com a definição de um objeto de estudo específico à cada ciência. Diante disso, 
questiona-se o valor científico da Geografia pelo fato de significativa parcela de seus estudos estarem voltados ao conhecimento detalhado de áreas reduzidas. Primeiro, é importante lembrar que o conhecimento de um grande número de lugares é uma demanda real e interessa a muitos. Segundo, se a busca por leis for o propósito final de um estudo, trata-se de uma postura indiscutivelmente dogmática. Quanto à exigência de que uma ciência possua um objeto específico para estudo, isso vai depender da natureza do conhecimento envolvido. É por isso que Hartshorne chama atenção para o fato de que, mais do que tentar enquadrar todos os tipos de conhecimento em um único padrão científico, é mais útil questionar que espécie de ciência cada uma representa. A Geografia, empenhada no desafio de interpretar e explicar o caráter variável da superfície terrestre, observa ele, tem um papel fundamental na produção de conhecimento sobre o mundo e seus lugares. Trata-se de uma ciência muito mais fundamentada em um método próprio do que em objetos específicos. Em citação sobre Richthofen (1883), Hartshorne (1978, p. 32) diz que esse geógrafo reconheceu, desde cedo, "que a Geografia não poderia pretender um lugar específico no mundo das ciências em termos de qualquer categoria particular de fenômenos, mas em função do seu ponto de vista e do seu método". Seguindo essa premissa, Hartshorne defende a Geografia, conforme observa Claval (1981), como uma ciência-método, residindo nessa característica a sua diferença em relação à maioria de outras disciplinas.

O processo de diferenciação representa a força do método nas concepções de Hartshorne. No entanto, como salienta o autor, tal conceito geralmente é alvo de críticas não necessariamente pela sua fundamentação teórica, mas "por aquilo que o crítico infere meramente através de sua interpretação das palavras que a constituem” (Hartshorne, 1978, p. 13). É comum, por esse motivo, a expressão “diferenciação de áreas" ser taxada erroneamente de mera descrição ou recaída ao modelo neopositivista de análise e interpretação. Segundo Hartshorne, o conceito decorre de uma síntese efetuada por Richthofen dos pontos de vista de Humboldt e Ritter e exposta de maneira mais completa por Hettner. Ele optou por manter a expressão, dando-lhe uma fundamentação ainda mais rica, porque, além de clássica, foi adotada por uma significativa parcela de geógrafos alemães, alguns dos quais influenciados pelo neokantismo. Talvez em função desse vínculo teórico, Hartshorne tenha demonstrado maior interesse ao aspecto funcional das áreas do que, necessariamente, aos elementos que 
dizem respeito, por exemplo, a processos advindos das relações sociais de produção.

É importante salientar essa observação porque, no que concerne à realidade social, falar de "diferença" é indispensável mas insuficiente no que tange a outras dimensões que também precisam ser evidenciadas, como a desigualdade, até porque ela também possui uma manifestação variável do ponto de vista espacial - o que, no entanto, não nos permite concebê-la como sinônimo de diferença, mas sim como relação social específica em função do modo como afeta a sociedade e por ela é produzida. Diante disso, por mais que diferença e variação sejam atributos fundamentais dos fenômenos, sobretudo humanos, é necessário destacar até que ponto esses conceitos possibilitam pensar a realidade humana e em que medida apresentam limites ao debate sobre dimensões da sociedade que a Geografia não pode deixar de vislumbrar.

\section{Diferença, funcionalidade e desigualdade: ainda uma questão}

A diferenciação, conforme demostrado, representa um caminho que nos possibilita compreender o caráter variável dos lugares. É certo que Hartshorne tenha chamado atenção à integração de fenômenos em seus aspectos fundamentalmente humanos, o que pode ser evidenciado em sua análise sobre regiões funcionais ou em seu artigo intitulado "The Functional Approach in Political Geography” (Hartshorne, 1950). A concepção funcional, que enfatiza a atuação de forças internas e externas na organização de determinado território, expõe também a relação entre fenômenos de diferentes regiões. Valendo-se desse raciocínio, Hartshorne fundamenta o conceito de região funcional, em que, mais uma vez, destaca o papel das relações. A região funcional, adverte o autor, não significa "uma generalização descritiva do caráter de uma área, mas a expressão de uma teoria de relações de processos. [...] Cada região funcional específica possui tamanho, forma, estrutura e configuração de movimentos internos que lhe são próprios” (Hartshorne, 1978, p. 144-145).

É importante mencionar o destaque dado à funcionalidade das regiões porque, além de representar um avanço nas discussões sobre a dinâmica dos lugares, os aspectos humanos são mantidos no centro da questão. Contudo, se as relações que Hartshorne enfatiza possuem aspectos essencialmente humanos, a busca pela compreensão do caráter 
variável da superfície terrestre suscita uma questão relacionada não apenas à noção de diferença ou diferenciação, mas também à de desigualdade. Isso deve ser discutido porque essas noções, especialmente na condição de conceitos, não podem ser tratadas como sinônimos. Moreira (1999) observa que diferença em Geografia, especialmente sob a perspectiva de Hartshorne, é diferenciação. A discussão, nesse viés, tem se distanciado de seu sentido ontológico, aproximando-se muito mais de uma análise da diferença entre entes do que necessariamente do ser desses entes. Isso, obviamente, tem situado a diferenciação como resultado das variações de múltiplos fenômenos, até mesmo de caráter social. O conceito de espacialidade diferencial de Lacoste (1988) é um exemplo. Por isso, ainda que algumas situações se enquadrem perfeitamente na ideia de diferença ou de diferenciação, outras exigem conceitos mais coerentes, como o de desigualdade, mais apropriado para ilustrar processos desencadeados por relações sociais de produção, as quais são muito bem discutidas por Lefebvre (1973). Em muitos casos, no entanto, desigualdade é tratada como um tipo específico de diferença, o que se apresenta, tanto do ponto de vista etimológico como conceitual, incorreto.

Barros (2006, p. 200) defende que desigualdade e diferença "não são noções necessariamente interdependentes, embora possam conservar relações bem definidas no interior de determinados sistemas sociais e políticos”. A desigualdade relaciona-se ao estar ou ao ter. Isto é: tem-se mais riqueza, mais liberdade, mais direitos ou privilégios etc. A diferença, por conseguinte, é mais relacionada ao ser (ser negro, ser mulher etc.), o que também vale para objetos e fenômenos. No âmbito espacial, por exemplo, a diferença também diz respeito à condição ontológica do modo como os fenômenos se inter-relacionam e caracterizam um lugar como singular. Os polos da diferença não são necessariamente contraditórios, tal como no caso da desigualdade. Concentração e centralização de capital, por exemplo, trazem como consequência a desigualdade espacial em função da transferência de valor de uma região para outra, tal como discute Viana (2000). Esse processo, obviamente, envolve um conjunto de relações que evidenciam a região ou área como arena política onde grupos de atores impõem suas ações, tal como observa Arrais (2007).

É por isso que a desigualdade, no âmbito das relações sociais de produção, é uma produção/imposição, o que a caracteriza como eminentemente circunstancial e histórica. É importante destacar esse elemento 
porque, mesmo que seu sentido ideológico nos faça pensar diferente, a desigualdade é reversível. A diferença, na maioria dos casos, é irreversível, o que a circunscreve no patamar da interpretação e não necessariamente da transformação. É por isso que as lutas sociais, salienta Barros (2006, p. 201), "não se orientam em geral para abolir as diferenças, mas sim para abolir ou minimizar as desigualdades". Isso traz um desafio à ciência porque, caso ela se dê apenas ao trabalho de interpretar os fenômenos, especialmente quando considere-se o conjunto de relações em seus aspectos humanos, ela reafirma a desigualdade no âmbito da irreversibilidade e, de fato, passa a confundi-la como sinônimo de diferença.

É certo que o conceito de diferença não diz respeito apenas à diversidade humana em seus aspectos ontológicos. Ele também se insere no âmbito das relações sociais e do caráter variável dos lugares. Muitos autores, a exemplo de Ortiz (1994) e Brah (2006), falam de diferenças culturais, sociais etc. Mas é certo também que, em muitas situações, a problemática da relação entre fenômenos, sobretudo sociais, diz respeito essencialmente à desigualdade e não, necessariamente, à diferença. Diferença e desigualdade, nesse sentido, são noções complexas. A sua utilização tem relação com o ponto de vista ou posicionamento político do pesquisador e implica, evidentemente, esforço de reflexão porque algumas situações exigem, até mesmo, outros conceitos. Mas também pode haver situações que demandam a capacidade de articulação de ambos, diferença e desigualdade, a exemplo daquelas que envolvem segregação social ou até mesmo questões advindas da modernização territorial. Nessas situações, há razões que realmente perpassam as relações mútuas e de conexões entre fenômenos, mas especialmente por uma dialética que envolve relação entre forma e processos sociais.

Por mais que haja um caráter variável dos lugares em função da inter-relação entre fenômenos nesses e entre esses lugares, o modo como são produzidos e incrementados pelos sujeitos e/ou grupos sociais - por meio, por exemplo, da implantação de redes técnicas e de elementos tecnológicos e infraestruturais - torna esses lugares essencialmente desiguais porque "isso é feito para garantir vantagens a determinados grupos e, ao mesmo tempo, para privar essas vantagens de outros grupos" (Castilho, 2014, p. 193). Esse fato nos permite dizer, conforme salientamos em outro trabalho, que o avanço das redes técnicas forma necessariamente espaços privilegiados (ou espaço dos privilégios) para atender a determinados 
grupos que, em função disso, também ocupam posições privilegiadas: "A formação desses espaços por meio das redes técnicas, por conseguinte, é fruto da desigualdade espacial e não, necessariamente, da diferenciação espacial" (Castilho, 2014, p. 194).

Como resultado de um tipo especial de relação, no caso, as relações sociais de produção, a desigualdade realmente se constitui como categoria de variação. Mas ela não pode ser concebida apenas como realidade cognoscível limitada à capacidade mental de um investigador. É certo que o caminho de análise do caráter variável da superfície terrestre proposto por Hartshorne, fruto da influência dos geógrafos alemães mas também dos avanços empreendidos pelo autor, permite interpretar contradições fundamentais. Todavia, essa proposta não vislumbra uma teoria necessária para superá-las. Isso significa que, do ponto de vista teórico-metodológico, o problema não é o fato de Hartshorne ter dado prioridade a esse ou aquele conceito, mas ao modo como sua teoria permite abordar determinado tema.

Portanto, se há integração de fenômenos que estão no eixo essencial da diferença, também há relações e processos sociais que se colocam no eixo circunstancial da desigualdade. Há integração de fenômenos que realmente são fontes de diferenciação. Mas também há processos sociais que produzem fundamentalmente desigualdade, não apenas diferença.

\section{Considerações finais}

O pensamento geográfico é daqueles que se encontram em construção. Limitado como qualquer outro campo disciplinar, é impossível imaginar quando e como ele virá a ser concluído. É justamente esse o atributo que justifica a continuidade das incertezas e das questões. Hartshorne, sem dúvida, foi um dos pensadores que atribuiu grande destaque à característica evolutiva da Geografia, motivo pelo qual sua obra é tida por Capel (2012) como uma das evidentes exposições da concepção historicista da geografia.

A construção desse conhecimento, para Hartshorne, não pode ser feita sem se considerar a essência que vem de sua tradição. Além de sistematizar as ideias produzidas por importantes clássicos da Geografia e de propor a superação do dualismo nessa disciplina, Hartshorne também sublinha a importância do tempo em Geografia - ao contrário do que supõem as críticas que atribuem às suas proposições negligência com a dimensão temporal. 
Nas palavras do próprio autor: “os geógrafos estudam o passado não só como a chave do presente, mas também em função do seu próprio conteúdo geográfico" (Hartshorne, 1978, p. 90). O que ele ressalta, no entanto, e disso pode decorrer a confusão, é o fato de interessar à Geografia os estudos de integrações em mudança desde que o centro da atenção "se conserve ao caráter das áreas, que muda em consequência de certos processos, em contraste com o interesse histórico pelos processos em si mesmos” (p. 114).

As observações levantadas neste artigo, embora suscitem questões sobre alguns conceitos presentes nos trabalhos de Hartshorne, ressalta a importância de suas proposições e sua inegável contribuição ao estudo do pensamento geográfico. A defesa de uma Geografia que se defina por um método próprio, empreendida por autores muito bem assimilados e difundidos por Hartshorne, ainda alcança expressão neste início de século XXI. Por mais que conceitos e categorias bastante expressivos no âmbito dos estudos geográficos contemporâneos não sejam exatamente aqueles propostos por Hartshorne, e por mais que eles sejam construídos por caminhos distintos daqueles que influenciaram esse autor, eles não deixam de traduzir a força do método ou a busca por um ponto de vista próprio à ciência geográfica. Além disso, quando ressaltamos duas noções bastante eminentes nos trabalhos de Hartshorne, relação e conexão, estamos chamando atenção à valorização dada às integrações e ao fato de que a realidade vislumbrada pela Geografia forma um conjunto. Esperamos que esta breve discussão seja um convite à leitura da obra desse autor, sobretudo considerando a sua importância para a Geografia, mas também a necessidade de sua contextualização e superação, mesmo porque é na tensão entre a tradição e os novos questionamentos que construímos uma postura de investigação. E se Hartshorne (1978, p. 8) entende que "a Geografia é o que os geógrafos dela fizeram”, vale dizer que ela também é o que dela continua a ser feito.

\section{Notas}

$1 \mathrm{Em}$ função de seus estudos relacionados à Geografia política, durante a Segunda Guerra Mundial, Hartshorne atuou como diretor da Divisão Geográfica do Departamento de Investigação e Análise do Escritório de Serviços Estratégicos (Office of Strategic Services - OSS), o serviço de inteligência dos Estados Unidos naquele período (MARTIN, 1994). 
20 único, nesses termos, diz respeito a combinação de fenômenos - diferente, por exemplo, da concepção de geógrafos franceses (como Paul Vidal de La Blache) que demonstram preocupação com o caráter único das áreas ao referir-se a elas como "indivíduos" (Hartshorne, 1951).

3 No âmbito dessa discussão, Wardenga e Harvey (1998) defendem que Hettner lidava mais com a teoria da representação geográfica do que necessariamente com uma metodologia para a pesquisa geográfica. Dizer que a Geografia, na concepção de Hettner, é a ciência da diferenciação de áreas, portanto, é precipitado - mesmo que ele tenha exposto esse conceito de maneira aprofundada. Isso porque a meta de sua perspectiva corológica diz respeito ao caráter da área, não ao método.

4 Essa passagem consta do relato de Thomas F. Glick (1985) sobre a crise da Geografia na Universidade de Harvard. Na ocasião, um comitê havia sido montado para analisar o sentido e o papel da disciplina na instituição. Importantes nomes da Geografia estadunidense foram chamados para dar suas opiniões sobre o tema, dentre eles Hartshorne. Dos oito integrantes do comitê, no entanto, apenas um era geógrafo, Edward Ullman, o qual deixou registrado importantes reflexões sobre a Geografia. O contexto, os debates e posicionamentos tanto dos professores de Harvard como dos convidados fazem dos documentos internos desse comitê, observa Glick (1985), uma importante fonte de estudo da história da Geografia estadunidense.

\section{Referências}

ARCASSA, W. S. Contribuições epistemológicas de Richard Hartshorne à Geografia moderna. Contribuciones a las Ciencias Sociales, Malaga, abr. 2013. Disponível em: <http://www.eumed.net/rev/cccss/24/richard-hartshornegeografia-moderna.html>. Acesso em: 08 abr. 2015.

. Richard Hartshorne: a discussão metodológica aos novos horizontes da geografia política. 2014. 110 f. Dissertação (Mestrado em Geografia) Departamento de Geociências, Universidade Estadual de Londrina, Londrina, 2014.

ARRAIS, T. A. A região como arena política. Goiânia: Vieira, 2007.

BARROS, J. D'A. Igualdade, desigualdade e diferença: contribuições para uma abordagem semiótica das três noções. Revista de Ciências Humanas, Florianópolis, n. 39, p. 199-218, abr. 2006.

BRAH, A. Diferença, diversidade, diferenciação. Cadernos Pagu, n. 26, p. 329376, jan.-jun. 2006. 
CAPEL, H. Filosofía y ciencia en la Geografía contemporánea: una introducción a la Geografia. (Nova edição ampliada). Barcelona: Ediciones del Serbal, 2012.

CASTILHO, D. Modernização territorial e redes técnicas em Goiás. 2014. 221 f. Tese (Doutorado em Geografia). Universidade Federal de Goiás, Goiânia, 2014.

CLAVAL, P. Evolución de la Geografía Humana. 2. ed. Barcelona: Oikos-Tau, 1981.

COSCIONI, F. J. O propósito da Geografia e a relação entre os enfoques sistemático e regional na obra de Richard Hartshorne. 2015. 132 f. Dissertação (Mestrado em Geografia Humana) - Faculdade de Filosofia, Letras e Ciências Humanas, Universidade de São Paulo, São Paulo, 2015.

GLICK, T. F. Antes de la revolución cuantitativa: Edward Ullman y la crisis de la Geografía en Harvard (1949-1950). Geocrítica - Cuadernos Críticos de Geografía Humana, n. 55, jan. 1985.

HARTSHORNE, R. Location as a Factor in Geography. Annals of the Association of American Geographers, v. 17, n. 2, p. 92-99, 1927.

. The Nature of Geography: A Critical Survey of Current Thought in the Light of the Past. Annals of the Association of American Geographers, v. 29, n. 3-4, p. 173-658, 1939.

. The Nature of Geography. 4 ${ }^{\mathrm{a}}$ impressão. Lancaster - Pennsylvania: Association of American Geographers, 1951.

. The Functional Approach in Political Geography. Annals of the $\bar{A}$ ssociation of American Geographers, v. 40, n. 2, p. 95-130, 1950.

The Concept of Geography as a Science of Space, from Kant and Humboldt to Hettner. Annals of the Association of American Geographers, v. 48, n. 2, p. 97-108, 1958.

. Perspective on the Nature of Geography. Chicago: Rand McNally, 1959.

. Propósitos e natureza da Geografia. Tradução de Thomaz Newlands Neto. 2. ed. São Paulo: Hucitec, 1978.

HETTNER, A. A geografia como ciência corológica da superfície terrestre. Tradução de Leonardo Arantes. GEOgraphia, Rio de Janeiro, v. 13, n. 25, p. 136-152, 2011a. Disponível em: <http://www.uff.br/geographia/ojs/index.php/ geographia/article/view/409/318>. Acesso em: 20 dez. 2014.

. A essência e as tarefas da Geografia [Das Wesen und die Aufgaben der Geographie]. Tradução de Leonardo Arantes. GEOgraphia, Rio de Janeiro, v. 13, n. 26, p. 136-149, 2011b. Disponível em: <http://www.uff.br/geographia/ojs/ index.php/geographia/article/view/458/328>. Acesso em: 09 ago. 2014.

LACOSTE, Y. A geografia: isso serve, em primeiro lugar, para fazer a guerra. Tradução de Maria Cecília França. Campinas: Papirus, 1988.

LEFEBVRE, H. A reprodução das relações de produção. Tradução de Antonio Ribeiro e M. do Amaral. Porto: Publicações Escorpião, 1973. 
LIMA NETO, E. M. Sobre a natureza da Geografia entre Richard Hartshorne e Fred K. Schaefer: um fragmento inacabado. 2012. 142 f. Dissertação (Mestrado em Geografia Humana) - Faculdade de Filosofia, Letras e Ciências Humanas, Universidade de São Paulo, São Paulo, 2012.

MARTIN, G. J. In Memoriam - Richard Hartshorne, 1899-1992. Annals of the Association of American Geographers, v. 84, n. 3, p. 480-492, 1994.

MORAES, A. C. R. Geografia: pequena histórica crítica. 18. ed. São Paulo: Hucitec, 2002.

MOREIRA, R. A diferença e a geografia: o ardil da identidade e a representação da diferença na Geografia. GEOgraphia, Rio de Janeiro, Ano 1, n. 1, p. 41-58, 1999.

O pensamento geográfico brasileiro: as matrizes clássicas originárias.

São Paulo: Contexto, 2008. v. 1.

ORTIZ, R. Mundialização e cultura. São Paulo: Brasiliense, 1994.

RICHTHOFEN, Ferdinand von. Aufgaben und methoden der heutigen Geographie. Akademische Antrittsrede. Leipzig: Acak, 1883.

SANTOS, D. Kant: o puro e o prático (impuro?). In: . A reinvenção do espaço: diálogos em torno da construção do significado de um conceito. São Paulo: Unesp, 2002. p. 174-185.

SAUER, C. Foreword to Historical Geography. Annals of the Association of American Geographers, v. 31, n. 1, 1941.

SCHAEFER, F. K. Excepcionalism in Geography: a methodological examination. Annals of the Association of American Geographers, v. 43, n. 3, p. 226-249, 1953.

VIANA, N. Capital, espaço e desigualdade. Boletim Goiano de Geografia, Goiânia, v. 20, n. 1, 2000.

WARDENGA, U.; HARVEY, F. The Hettner-Hartshorne connection: reconsidering the process of reception and transformation of a geographic concept. Finnisterra - Revista Portuguesa de Geografia, Lisboa, v. XXXIII, n. 65, p. 131-140, 1998.

Denis Castilho - Possui doutorado em Geografia pela Universidade Federal de Goiás. Atualmente é professor adjunto do Instituto de Estudos Socioambientais da UFG e coordenador do Grupo de Pesquisa em Teoria e Metodologia da Geografia (GEOtema).

Recebido para publicação em 21 de outubro de 2015 Aceito para publicação em 29 de novembro de 2015 